\title{
Complete Mitochondrial Genomes of Three Nuthatches From the Genus Sitta (Aves: Passeriformes: Sittidae) and Mitogenome-Based Phylogenetic Analysis
}

\section{Qing-Miao Yuan}

Southwest Forestry University

Xu Luo

Southwest Forestry University

Jing Cao

Administration of Zixi Mountain Provincial Nature Reserve

Yu-Bao Duan ( $\sim$ boyciana@163.com)

Southwest Forestry University

\section{Research Article}

Keywords: Sitta, Mitochondrial genome, Phylogeny

Posted Date: December 28th, 2021

DOI: https://doi.org/10.21203/rs.3.rs-1097909/v1

License: () (1) This work is licensed under a Creative Commons Attribution 4.0 International License. Read Full License 


\section{Abstract \\ Background}

Nuthatches (genus Sitta) comprise a group of Passeriformes. With the publication of more mitochondrial genome data, there has been considerable focus on the taxonomic status of the nuthatches. To understand the phylogenetic position of Sitta and phylogenetic relations within this genus, we sequenced and analyzed the complete mitochondrial genomes of three species, S. himalayensis, S. nagaensis and S. yunnanensis, making this the first account of complete mitochondrial genomes (mitogenomes) for this genus.

\section{Results}

The mitochondrial genomes of three Sitta species are 16,822-16,830 bp in length and consisted of 37 genes and a control region. This study recovered the same gene arrangement found in the mitogenomes of Gallus gallus, which is considered the typical ancestral avian gene order. All tRNAs were predicted to form the typical cloverleaf secondary structures. Bayesian inference and maximum likelihood phylogenetic analyses of sequences of 18 species obtained a well-supported topology. The family Sittidae is the sister-group of Troglodytidae, and the genus Sitta can be divided into 3 major clades. We demonstrated the phylogenetic relationships within genus Sitta (S. carolinensis + (S. villosa + S. yunnanensis + (S. himalayensis + (S. europaea + S. nagaensis))))

\section{Background}

The avian mitochondrial genome is characterized with a small size, relatively fast rate of evolution, and strict maternal inheritance in genetics, and is easy to extract and amplify, which makes it an ideal marker for the evolutionary analyses at the molecular level [1, 2, 3]. The avian mitogenome is a double-stranded circular molecule composed of a light strand (L-strand) and a heavy strand ( $\mathrm{H}$-strand), ranging from 16.3-23.1 kb in length [4], and consists of 1 or 2 control region(s), 13 protein-coding genes (PCGs), 22 transfer RNA genes (tRNAs) and 2 ribosomal RNA genes (rRNAs) [5, 6, 7]. The mitogenome plays an important role in revealing the origin and phylogeny of birds [8].

The genus Sitta, which belongs to the subfamily Sittinae (Passeriformes, Sittidae), includes 29 species of genus Sitta known around the world, 11 of which are distributed in China [9]. Although many molecular data have been published, the phylogenetic relationship of the family Sittidae remains controversial. Ericson and Johansson (2003) placed the family Sittidae within Sylvioidea [10]. In recent years, it has also been proposed that Sittidae belongs to Certhioidea [11, 12]. Johansson et al. (2008) supported that Sittidae is sister to Polioptilidae and Troglodytidae [11], while Treplin et al. (2010) proposed that Sittidae is sister to Certhiidae and Troglodytidae [13]. Later research results showed that Sittidae and Troglodytidae were closely related [14]. These controversies are mainly generated by limited mitochondrial genome data. Therefore, more molecular data are necessary to reconstruct precise phylogeny [15].

Currently, the data of complete mitogenome from the genus Sitta are very scarce. In order to better understand the relationships among the species of Sitta, we sequenced three mitogenomes of the genus Sitta and compared them with related species in terms of mitochondrial structure and gene rearrangement. In this study, we report the properties of the mitogenomes of three Sitta species, and infer the phylogenetic relationships of the species with available mitogenome sequences using all PCGs.

\section{Results And Discussion Genome organization}

The complete mitogenomes of the three newly sequenced Sitta species are very similar to each other. All three mitogenomes are closed circular molecules ranging from 16,822 to 16,830 bp in length, consisting of 13 PCGs, 22 tRNAs, 2 rRNAs and a control region (Fig. 1). The gene order of mitogenomes of all three species analyzed are highly conserved (Fig. 1), which is also identical to the gene order found in the mitogenome of Gallus gallus [16]. For the whole mitogenomes of the three species, one PCG (nad6) and eight tRNAs ( $\operatorname{trn} Q, \operatorname{trn} A, \operatorname{trnN}, \operatorname{trnC}, \operatorname{trn} Y, \operatorname{trnS} 2(\mathrm{UCM}), \operatorname{trn} P$, $\operatorname{trn} E)$ are encoded by the L-strand, while all the other genes are encoded by the $\mathrm{H}$-strand. The comparison of the three Sitta species discovered the longest overlap (10 bp) between atp8 and atp6. The longest intergenic spacer (21 bp) is located between $\operatorname{trnV}$ and $r m L$ in mitogenome of $S$. himalayensis (Table 1). Similar to other typical vertebrates [17], the mitogenomes of the three Sitta species show a significant bias towards A and T, with the nucleotide composition of A and T ranging from 53.1-55.7\%. The AT-skew and the GC-skew of the whole mitogenomes of three Sitta species are 0.10 to 0.13 and -0.39 to -0.35 , respectively (Table 2). 
Table 1

Annotation of the complete mitogenome of the three Sitta species in this study

\begin{tabular}{|c|c|c|c|c|c|}
\hline Gene & Start codon & Stop codon & Anti-codon & Strand & $\begin{array}{l}\text { Intergenic } \\
\text { Nucleotides (IGN) }\end{array}$ \\
\hline $\operatorname{trn} F$ & & & GAA & $\mathrm{H}$ & -1 \\
\hline$r r n S$ & & & & $\mathrm{H}$ & $0(a) /-1(b, c)$ \\
\hline $\operatorname{trn} V$ & & & TAC & $\mathrm{H}$ & $21(a) / 2(b, c)$ \\
\hline$r r n L$ & & & & $\mathrm{H}$ & $2(a) / 1(b) / 7(c)$ \\
\hline $\operatorname{trn} L 2(U U R)$ & & & TAA & $\mathrm{H}$ & $11(a, c) / 12(b)$ \\
\hline nad1 & ATG & $\mathrm{TAA} / \mathrm{TA}(\mathrm{A}) / \mathrm{TAG}$ & & $\mathrm{H}$ & $7(a, c) / 10(b)$ \\
\hline $\operatorname{trnl}$ & & & GAT & $\mathrm{H}$ & 6 \\
\hline $\operatorname{trn} Q$ & & & TTG & $\mathrm{L}$ & $4(a) / 3(b) / 2(c)$ \\
\hline $\operatorname{trn} M$ & & & CAT & $\mathrm{H}$ & $1(a, b) / 0(c)$ \\
\hline nad2 & ATG & TAA & & $\mathrm{H}$ & 1 \\
\hline $\operatorname{trn} W$ & & & TCA & $\mathrm{H}$ & 1 \\
\hline $\operatorname{trn} A$ & & & $\mathrm{TGC}$ & $\mathrm{L}$ & 10 \\
\hline $\operatorname{trn} N$ & & & GTT & $\mathrm{L}$ & $2(a, c) / 11(b)$ \\
\hline $\operatorname{trn} C$ & & & GCA & $\mathrm{L}$ & -1 \\
\hline $\operatorname{trn} Y$ & & & GTA & $\mathrm{L}$ & 1 \\
\hline $\operatorname{cox} 1$ & GTG & AGG & & $\mathrm{H}$ & -9 \\
\hline $\operatorname{trnS} 2(U C M)$ & & & TGA & $\mathrm{L}$ & 4 \\
\hline $\operatorname{trn} D$ & & & GTC & $\mathrm{H}$ & $10(a) / 11(b, c)$ \\
\hline $\operatorname{cox} 2$ & ATG & TAA & & $\mathrm{H}$ & 1 \\
\hline $\operatorname{trnK}$ & & & TTT & $\mathrm{H}$ & 1 \\
\hline atp8 & ATG & TAA & & $\mathrm{H}$ & -10 \\
\hline atp6 & ATG & TAA & & $\mathrm{H}$ & $9(a, b) / 11(c)$ \\
\hline $\operatorname{cox} 3$ & ATG & $\mathrm{TA}(\mathrm{A})$ & & $\mathrm{H}$ & -1 \\
\hline $\operatorname{trn} G$ & & & $\mathrm{TCC}$ & $\mathrm{H}$ & 0 \\
\hline nad3 & ATG & TAA & & $\mathrm{H}$ & -1 \\
\hline $\operatorname{trn} R$ & & & TCG & $\mathrm{H}$ & 1 \\
\hline $\operatorname{nad} 4 \mathrm{~L}$ & ATG & TAA & & $\mathrm{H}$ & -7 \\
\hline nad4 & ATG & $\mathrm{T}(\mathrm{AA})$ & & $\mathrm{H}$ & 0 \\
\hline $\operatorname{trnH}$ & & & GTG & $\mathrm{H}$ & 0 \\
\hline $\operatorname{trnS1}(A G M)$ & & & GCT & $\mathrm{H}$ & -1 \\
\hline $\operatorname{trn} L 1(C U N)$ & & & TAG & $\mathrm{H}$ & $1(a) / 0(b, c)$ \\
\hline nad5 & ATG & AGA & & $\mathrm{H}$ & 11 \\
\hline Cytb & ATG & TAA & & $\mathrm{H}$ & $6(a) / 3(b, c)$ \\
\hline $\operatorname{trn} T$ & & & TGT & $\mathrm{H}$ & $7(a) / 8(b, c)$ \\
\hline $\operatorname{trn} P$ & & & TGG & $\mathrm{L}$ & $14(a, b) / 6(c)$ \\
\hline nad6 & ATG & TAG & & $\mathrm{L}$ & 0 \\
\hline $\operatorname{trn} E$ & & & TTC & $\mathrm{L}$ & $4(a) / 5(b, c)$ \\
\hline $\mathrm{CR}$ & & & & $\mathrm{H}$ & $279(a) / 282(b) / 266(c)$ \\
\hline
\end{tabular}


Table 2

Nucleotide composition of the mitochondrial genome of the three Sitta species in this study

\begin{tabular}{|c|c|c|c|c|c|c|c|c|c|c|c|c|c|c|c|c|c|}
\hline \multirow[t]{2}{*}{ Species } & \multicolumn{3}{|c|}{ Whole genome } & \multicolumn{3}{|c|}{ PCGs } & \multicolumn{3}{|c|}{ tRNAs } & \multicolumn{3}{|c|}{ 16S rRNA } & \multicolumn{3}{|c|}{ 12S rRNA } & \multicolumn{2}{|c|}{ Control region } \\
\hline & $\begin{array}{l}A+T \\
(\%)\end{array}$ & $\begin{array}{l}\text { AT } \\
\text { skew }\end{array}$ & $\begin{array}{l}\text { GC } \\
\text { skew }\end{array}$ & $\begin{array}{l}A+T \\
(\%)\end{array}$ & $\begin{array}{l}\text { AT } \\
\text { skew }\end{array}$ & $\begin{array}{l}\text { GC } \\
\text { skew }\end{array}$ & $\begin{array}{l}A+T \\
(\%)\end{array}$ & $\begin{array}{l}\text { AT } \\
\text { skew }\end{array}$ & $\begin{array}{l}\text { GC } \\
\text { skew }\end{array}$ & $\begin{array}{l}A+T \\
(\%)\end{array}$ & $\begin{array}{l}\text { AT } \\
\text { skew }\end{array}$ & $\begin{array}{l}\text { GC } \\
\text { skew }\end{array}$ & $\begin{array}{l}\text { A+T } \\
(\%)\end{array}$ & $\begin{array}{l}\text { AT } \\
\text { skew }\end{array}$ & $\begin{array}{l}\text { GC } \\
\text { skew }\end{array}$ & $\begin{array}{l}A+T \\
(\%)\end{array}$ & $\begin{array}{l}\text { AT } \\
\text { skew }\end{array}$ \\
\hline $\begin{array}{l}\text { S. } \\
\text { himalayensis }\end{array}$ & 53.9 & 0.13 & -0.38 & 53.1 & 0.07 & -0.41 & 58.3 & 0.03 & 0.02 & 55.6 & 0.24 & -0.12 & 51.2 & 0.18 & -0.11 & 54.6 & -0.15 \\
\hline S. nagaensis & 53.1 & 0.13 & -0.39 & 52.0 & 0.09 & -0.42 & 58.0 & 0.04 & 0.01 & 55.6 & 0.24 & -0.11 & 51.5 & 0.18 & -0.11 & 53.3 & -0.12 \\
\hline $\begin{array}{l}\text { S. } \\
\text { yunnanensis }\end{array}$ & 55.7 & 0.10 & -0.35 & 55.2 & 0.04 & -0.38 & 58.3 & 0.04 & 0.01 & 56.4 & 0.23 & -0.10 & 52.2 & 0.18 & -0.11 & 55.5 & -0.15 \\
\hline
\end{tabular}

\section{Protein-coding genes and codon usage}

In the three Sitta species, the scope of A + T content in PCGs is between $52.0 \%$ and $55.2 \%$ (Table 2). The start codons and stop codons of the 13 PCGs are mostly the same among the three species. cox 1 uses GTG as the start codon, while the rest twelve PCGs initiate strictly with the standard start codon ATG (Table 1). There are six kinds of stop codons (TAA, AGG, AGA, TAG, TA*, T**) included in the mitogenome of the three Sitta species. For the incomplete stop codons, the missing nucleotides may be the result of post-transcriptional polyadenylation [18], which is common in animal mitogenomes and could produce functional stop codons by polycistronic transcription cleavages and polyadenylation mechanisms $[18,19]$. The PCG nad1 in the mitochondrial genome of $S$. nagaensis contains the incomplete stop codon TA*, while TAN ( $\mathrm{N}$ represents $\mathrm{A}, \mathrm{G}$ ) occurs in the other two species. Except for nad1, all of the other PCGs use the same stop codon across the three Sitta species.

The relative synonymous codon usage (RSCU) of 13 PCGs in the three newly sequenced mitogenomes was calculated. As shown in Fig. 2, CGA (Arg) and CUA (Leu1) are most commonly used in all three Sitta species. The highest value of RSCU is 3.86 of CGA in S. yunnanensis and the lowest value of RSCU is 0.03 of UAG in S. himalayensis and S. nagaensis. In addition, analysis of the RSCU values for the 13 PCGs indicates an AT bias. As for PCGs, the AT bias can be attributed to the frequent use of NNA and NNU ( $N$ represents A, T, C, G) codons [20]. The A + T content in PCGs of $S$. yunnanensis is slightly higher than that of the other two species, and the use of NNA and NNU codons is also more common in S. yunnanensis.

\section{The tRNA genes and rRNA genes}

The 22 tRNAs of the three Sitta species are typical and include all 20 types of amino acids, ranging from 66 to 75 bp in size. And the total length of the 22 mitogenome tRNAs of $S$. nagaensis is $1542 \mathrm{bp}$, which is the same as that of S. yunnanensis and only one-base different from that of S. himalayensis. The A + T content of the total mitogenome tRNAs of $S$. nagaensis is $58.0 \%$, which is lower than that of $S$. himalayensis ( $58.3 \%)$ and $S$. yunnanensis ( $58.3 \%$ ) (Table 2). The tRNAs of three Sitta species were all predicted to fold into typical cloverleaf secondary structures. Furthermore, mismatched base pairs were identified in the stems of 22 different tRNAs, most of which were G-U pairs.

In the mitogenome of the three Sitta species, the $16 S$ rRNA is located between trnV and trnL2(UUR), ranging from 1575 to 1592 bp in length, while the $12 S$ $r R N A$ is located between trnF and trnV, ranging from 977 to $980 \mathrm{bp}$. The longest $16 S$ rRNA was found in S. nagaensis and the shortest in S. himalayensis, while the longest $12 S$ rRNA was discovered in S. yunnanensis and the shortest in S. himalayensis. The A + T contents of $16 S$ rRNA and $12 S$ rRNA range from $55.6-56.4 \%$ and from $51.2-52.2 \%$ respectively (Table 2 ).

\section{The control region}

The control region of the three species is located between trnE and trnF genes (Fig. 1). The size of control region of $S$. yunnanensis is 975 bp, which is longer than that of $S$. himalayensis (945 bp) and $S$. nagaensis (945 bp). The A + T content of the control region ranges from 53.3-55.5\% (Table 2). The AT-skew is -0.15 to -0.12 and the GC-skew is -0.22 , and the A + C content is higher than the T + G content. In this study, we analyzed the control region of three Sitta species and the predicted structures are shown in Figure 3. The entire control region contains three structural domains, namely Domain $\nabla$, Domain $\nabla$ and Domain $₫$. Domain $₫$ is relatively conservative, while Domain $\otimes$ and Domain $\otimes$ are heterogeneous across species in terms of nucleotide composition and size [21].

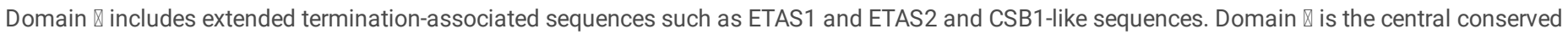

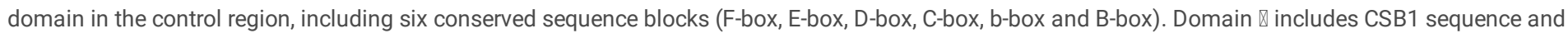
light/heavy strand promoter (LSP/HSP), which are located at 911-929 bp in the control region (Figure 3).

\section{Phylogenetic Analyses}

Based on the concatenated nucleotide sequences of 13 PCGs, the phylogenetic analyses of 18 Passeriformes mitogenome sequences were performed, with one of the Regulus species as the outgroup (Table 3). BI and ML analyses generated similar tree topologies, so the topology of the BI tree is shown (Fig. 4). The results of this study indicate that Sittidae is closely related to Troglodytidae ( 1.00 posterior probability and $95 \%$ bootstrap value). Muscicapidae and Turdidae were herein corroborated to be sister groups (1.00 posterior probability and $100 \%$ bootstrap value). These results are consistent with the work of Barker on the sister groups of Sittidae and Troglodytidae [14]. 
Table 3

List of 18 species used for the phylogenetic analyses in this study

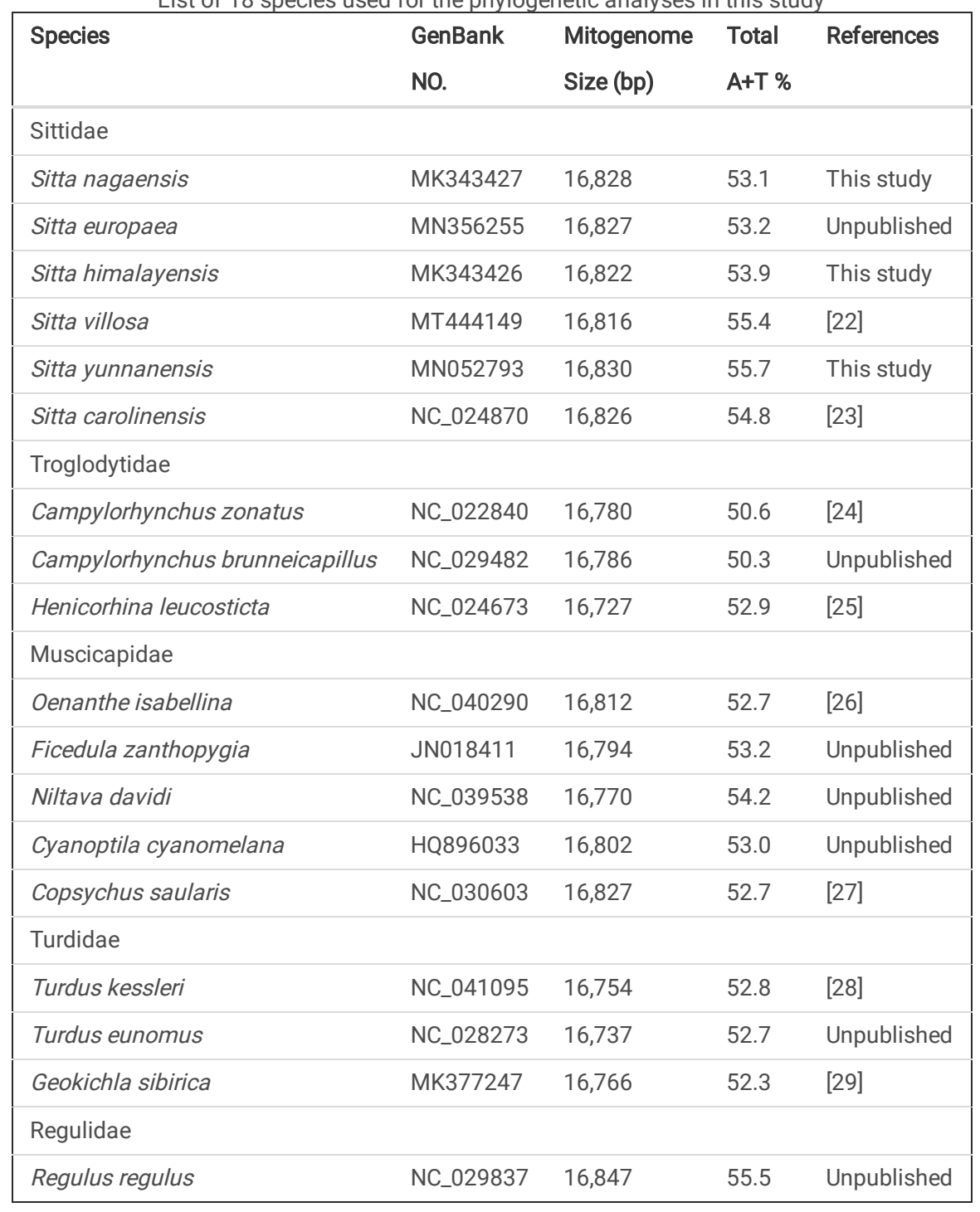

In the genus Sitta, S. nagaensis and S. europaea were found to be the sister to the $S$. himalayensis (1.00 posterior probability and $100 \%$ bootstrap value). $S$. villosa is the sister to $S$. yunnanensis (1.00 posterior probability and $100 \%$ bootstrap value). All datasets supported a monophyletic clade of $S$. carolinensis, which was placed at the basal position of the genus Sitta (1.00 posterior probability and $100 \%$ bootstrap value). These results are generally identical to the previous study conducted by Pasquet et al. [30]. Currently, published mitochondrial genome data of Sitta species are very limited, so mitochondrial genomes of more Sitta species should be sequenced to better elucidate these phylogenetic relationships.

\section{Materials And Methods}

\section{Samples and DNA Extraction}

Sample of Sitta himalayensis was collected in December 2018 from Gaoligong Mountain Nature Park of Yunnan Province, China, and samples of Sitta nagaensis and Sitta yunnanensis were collected in September 2018 from Zixi Mountain Provincial Nature Reserve of Yunnan Province, China. Voucher samples of three Sitta species were deposited in Department of Biodiversity Conservation, Southwest Forestry University, Kunming. Samples used in this study were preserved in ethanol absolute and stored at $-20^{\circ} \mathrm{C}$. The total genomic DNA was extracted from blood using the TIANamp Genomic DNA Kit (DP304, TIANGEN, Beijing, China) according to the manufacturer's protocol.

\section{Genome Sequencing, Assembly and Annotation}

As described in previous studies, the mitogenomes were amplified and sequenced [31, 32, 33]. All products of this study were sequenced by Shanghai Personal Biotechnology Co., Ltd (Shanghai, China). The complete mitogenomes of S. himalayensis, S. nagaensis and S. yunnanensis have been deposited in GenBank (Accession Numbers: MK343426, MK343427 and MN052793). Sequences were checked and assembled with SeqMan program of DNASTAR software [31]. Two rRNAs and all PCGs were identified by BLAST searches in NCBI (Available online: http://www.ncbi.nlm.nih.gov), and then confirmed by alignment with homologous genes from other published Sitta mitogenomes. The mitogenomic map was depicted with OGDRAW (https://chlorobox.mpimpgolm.mpg.de/OGDraw.html) [34]. Then 22 tRNAs were identified by tRNAscan-SE 2.0 and ARWEN (online version) [35, 36]. MEGA 7.0 was used to calculate the nucleotide composition and RSCU for PCG analysis [37]. The formulas AT-skew $=[$ A - T] $/[A+T]$ and GC-skew $=[G-C] /[G+C]$ were used for composition 
skew analysis [38]. The Tandem Repeats Finder program (Available online: http://tandem.bu.edu/trf/trf.advanced.submit.html) was used to analyze the tandem repeats of the putative control region [39]. Moreover, genome organization, base composition, intergenic spacers, overlapping regions, codon usage, PCGs, tRNAs, rRNAs and control region of the mitochondrial genomes of three Sitta species were compared.

\section{Phylogenetic Analyses}

The sequences of 15 published mitochondrial genomes were obtained from NCBI. These sequences, along with three new mitogenome sequences obtained in this study, were used to reconstruct the phylogenetic relationships within the genus Sitta, with Regulus regulus (Accession No. NC_029837) serving as an outgroup [14]. The sequence information is listed in Table 3.

The mitogenome sequences of the 13 PCGs were aligned using Clustal X in MEGA v.7.0 with the default parameters [40]. The length of the final alignment was 11,380 nucleotides. The substituted saturation of nucleotide sequences was analyzed with DAMBE 5.2.63 [41]. If Iss was significantly lower than Iss.c ( $p<$ 0.05), the whole PCG nucleotide sequences entered the next step. The Bayesian information criterion (BIC) in jModelTest v.0.1.1 [42] was used to determine the optimal nucleotide substitution model, which was $\mathrm{GTR}+\mathrm{G}+\mathrm{l}$. Bayesian inferences (BI) and maximum likelihood (ML) analyses were performed using MrBayes v.3.2.1 [43, 44] and RAxMLGUI v.1.5b3 [45], respectively. BI analyses initiated from a random tree, with four Markov chains running simultaneously for 200,000 generations, sampling every 100 generations and discarding the first $25 \%$ as burn-in. The average standard deviation of split frequencies was set below 0.01 to ensure that stationarity was reached. [46]. The confidence values of the BI tree were shown as Bayesian posterior probabilities. In ML analyses, a total of 1000 replicates were performed with the GTR+GAMMA substitution model. Finally, FigTree v.1.2.2 was used to visualize the phylogenetic trees [47].

\section{Declarations}

\section{Ethics approval and consent to participate}

All samples collected in this study were non-invasive sampling. All animal experiments were approved by the Academic Committee of Southwest Forestry University, which includes some regulations on animal ethics, animal welfare, and wildlife conservation. And all methods were performed in accordance with the the Guidelines for the ethical review of laboratory animal welfare People's Republic of China National Standard (GB/T 35892-2018) and the study complies with the ARRIVE guidelines (https://arriveguidelines.org).

\section{Consent for publication}

Not applicable.

\section{Availability of data and materials}

The newly described mitogenome sequences have been deposited in the NCBI database under the Accession numbers MK343426, MK343427 and MN052793. The datasets generated and/or analysed during the current study are available in the NCBI (https://www.ncbi.nlm.nih.gov/).

\section{Competing interests}

The authors declare no conflict of interest.

\section{Funding}

This work was supported by the Science and Technology Project of Yunnan (20210AT070040) and International Cooperation Fund for Giant Panda ([2017], No. 115).

\section{Authors' Contributions}

Xu Luo provided a sample of Sitta himalayensis. Qing-Miao Yuan and Yu-Bao Duan conceived and designed the experiments. Qing-Miao Yuan and Jing Cao performed the experiments. Qing-Miao Yuan analyzed the data and wrote the paper. Yu-Bao Duan revised the manuscript and provided advice and guidance.

\section{Acknowledgements}

We give our thanks to Shi-miao Shao (The First Affiliated Hospital, Zhejiang University School of Medicine) for revising the manuscript. We also thank the reviewers for their valuable comments and suggestions to improve the manuscript.

\section{Authors' information}

1. Department of Biodiversity Conservation, Southwest Forestry University, Kunming, Yunnan 650224, China

2. Key Laboratory for Conserving Wildlife with Small Populations in Yunnan, Southwest Forestry University, Kunming, 650224, China

3. Administration of Zixi Mountain Provincial Nature Reserve, Chuxiong, Yunnan 675000, China

\section{References}

1. Wolstenholme DR. Animal mitochondrial DNA: structure and evolution. Int Rev Cytol. 1992;141(6):173-216.

2. Boore JL. Animal mitochondrial genomes. Nucleic Acids Res. 1999;27(8):1767-1780. 
3. Taanman JW. The mitochondrial genome: structure, transcription, translation and replication. Biochimica et Biophysica Acta. 1999;1410(2):103-123.

4. Li QW, Li S, Tian CY, Wang YJ, Guo YM. Molecular evolution and variability in mitochondrial DNA in ten species of Passeriforme. Acta Zoologica Sinica. 2002;48(5):625-632.

5. Quinn TW. Molecular evolution of the mitochondrial genome-Chapter 1. Avian Molecular Evolution and Systematics. 1997;3-28.

6. Kan XZ, Li XF, Lei ZP, Wang M, Chen L, Gao H, Yang ZY. Complete mitochondrial genome of Cabot's tragopan, Tragopan caboti (Galliformes: Phasianidae). Genet Mol Res. 2010;9(2):1204-1216.

7. Zhou C, Hao YQ, Ma JN, Zhang WB, Chen YZ, Chen BP, Zhang XY, Yue BS. The first complete mitogenome of Picumnus innominatus (Aves, Piciformes, Picidae) and phylogenetic inference within the Picidae. Biochem Syst Ecol. 2017;70:274-282.

8. Podsiadlowski L, Kohlhagen H, Koch M. The complete mitochondrial genome of Scutigerella causeyae (Myriapoda: Symphyla) and the phylogenetic position of Symphyla. Mol Phylogenet Evol. 2007;45(1):251-260.

9. Zurita P, Dias B, Blackwood N. HBW-BirdLife Version 5.0 (2020). Available online: http://datazone.birdlife.org (accessed on 15 July 2021).

10. Ericson PGP, Johansson US. Phylogeny of Passerida (Aves: Passeriformes) based on nuclear and mitochondrial sequence data. Mol Phylogenet Evol. 2003;29(1):126-138.

11. Johansson US, Fjeldså J, Bowie RC. Phylogenetic relationships within Passerida (Aves: Passeriformes): a review and a new molecular phylogeny based on three nuclear intron markers. Mol Phylogenet Evol. 2008;48(3):858-876.

12. Zhao M, Alström P, Olsson U, Qu YH, Lei FM. Phylogenetic position of the Wallcreeper Tichodroma muraria. J Ornithol. 2016;157(3):913-918.

13. Treplin S, Siegert R, Bleidorn C, Thompson HS, Fotso R, Tiedemann R. Molecular phylogeny of songbirds (Aves: Passeriformes) and the relative utility of common nuclear marker loci. Cladistics. 2010;24(3):328-349.

14. Barker KF. Mitogenomic data resolve basal relationships among Passeriform and Passeridan birds. Mol Phylogenet Evol. 2014;79:313-324.

15. Chen ZT, Du YZ. First mitochondrial genome from Nemouridae (Plecoptera) reveals novel features of the elongated control region and phylogenetic implications. Int J Mol Sci. 2017;18(5):996.

16. Dejardins $P$, Morais R. Sequence and gene organization of the chicken mitochondrial genome: a novel gene order in higher vertebrates. $J$ Mol Biol. 1990;212(4):599-634.

17. Shadel GS, Clayton DA. Mitochondrial DNA maintenance in vertebrates. Annu Rev Biochem. 1997;66(1):409-435.

18. Ojala D, Montoya J, Attardi G. tRNA punctuation model of RNA processing in human mitochondria. Nature. 1981;290(5806):470-474.

19. Boore JL. Complete mitochondrial genome sequence of the polychaete annelid Platynereis dumerilii. Mol Biol Evol. 2001;18(7):1413-1416.

20. Li WJ, Wang ZQ, Che YL. The complete mitogenome of the Wood-Feeding Cockroach Cryptocercus meridianus (Blattodea: Cryptocercidae) and its phylogenetic relationship among cockroach families. Int J Mol Sci. 2017;18(11):2397.

21. Huang ZH, Liao XJ. Structure of the mitochondrial DNA control region and genetic variation of Chrysolophus pictus. Life Science Research. 2011;15:223228.

22. Zhang ZR, Mi SH, Guo QX, Zhang Z, Yan PF, Liu ZS, Teng LW. The complete mitochondrial genome of the Sitta villosa (Passeriformes: Sittidae) from China. Mitochondrial DNA Part B. 2020;5(3):2328-2329.

23. Barker FK. Mitogenomic data resolve basal relationships among passeriform and passeridan birds. Mol Phylogenet Evol. 2014;79:313-324.

24. Barker FK, Oyler-McCance S, Tomback DF. Blood from a turnip: tissue origin of low-coverage shotgun sequencing libraries affects recovery of mitogenome sequences. Mitochondrial DNA. 2013;26(3):384-388.

25. Aguilar C, Léon LFD, Loaiza JR, McMillan WO, Miller MJ. Extreme sequence divergence between mitochondrial genomes of two subspecies of Whitebreasted Wood-wren (Henicorhina leucosticte, Cabanis, 1847) from western and central Panamá. Mitochondrial DNA. 2016;27(2):956-957.

26. Li SB, Luo A, Li GP, Li W. Complete mitochondrial genome of the isabelline wheatear Oenanthe isabellina (Passeriformes, Muscicapidae). Mitochondrial DNA Part B. 2016;1(1):355-356.

27. Peng LF, Yang DC, Lu CH. Complete mitochondrial genome of oriental magpie-robin Copsychus saularis (Aves: Muscicapidae). Mitochondrial DNA Part B. 2016;1(1):21-22.

28. Song S, Qin JH, Luo JJ, Li DH, Jiang B, Chang C. Analysis of complete mitochondrial genome sequence of Kessleri thrush, Turdus kessleri (Passeriformes, Turdidae). Mitochondrial DNA Part B. 2018;2(3):818-819.

29. Sun CH, Liu B, Lu CH. Complete mitochondrial genome of the Siberian thrush, Geokichla sibirica sibirica (Aves, Turdidae). Mitochondrial DNA Part B. 2019;4(1):1150-1151.

30. Pasquet E, Barker FK, Martens J, Tillier A, Cruaud C, Cibois A. Evolution within the nuthatches (Sittidae: Aves, Passeriformes): molecular phylogeny, biogeography, and ecological perspectives. J Ornithol. 2014;155(3):755-765.

31. Liu G, Zhou LZ, Li B, Zhang LL. The complete mitochondrial genome of Aix galericulata and Tadorna ferruginea: bearings on their phylogenetic position in the Anseriformes. PLoS One. 2014;9(11):e109701-.

32. Zhang ZC, Cheng QQ, Ge YS. The complete mitochondrial genome of Rhynchocypris oxycephalus (Teleostei: Cyprinidae) and its phylogenetic implications. Ecol Evol. 2019;9:7819-7837.

33. Lu XT, Gong L, Zhang Y, Chen J, Liu LQ, Jiang LH, Lü ZM, Liu BJ, Tong GX, Wei XX. The complete mitochondrial genome of Calappa bilineata: the first representative from the family Calappidae and its phylogenetic position within Brachyura. Genomics. 2020;112(3):2516-2523.

34. Lohse M, Drechsel O, Bock R. OrganellarGenomeDRAW (OGDRAW): a tool for the easy generation of high-quality custom graphical maps of plastid and mitochondrial genomes. Curr Genet. 2007;52(5-6):267-274.

Page $7 / 11$ 
35. Lowe TM, Chan PP. tRNAscan-SE On-line: integrating search and context for analysis of transfer RNA genes. Nucleic Acids Res. 2016 ;W1:W54-W57.

36. Laslett D, Canback B. ARWEN: A program to detect tRNA genes in metazoan mitochondrial nucleotide sequences. Bioinformatics. 2008;24(2):172-175.

37. Sudhir K, Glen S, Koichiro T. MEGA7: molecular evolutionary genetics analysis version 7.0 for bigger datasets. Mol Biol Evol. 2016;33(7):1870-1874.

38. Perna NT, Kocher TD. Patterns of nucleotide composition at fourfold degenerate sites of animal mitochondrial genomes. J Mol Evol. 1995;41(3):353-358.

39. Gary B. Tandem repeats finder: a program to analyze DNA sequences. Nucleic Acids Res. 1999;27:573-580.

40. Larkin MA, Blackshields G, Brown NP, Chenna R, McGettigan PA, McWilliam H, Valentin F, Wallace IM, Wilm A, Lopez R, et al. ClustalW and ClustalX version 2.0. Bioinformatics. 2007;23:2947-2948.

41. Zhou XP, Lin QX, Fang WZ, Chen XL. The complete mitochondrial genomes of sixteen ardeid birds revealing the evolutionary process of the gene rearrangements. BMC Genomics. 2014;15(1):1-9.

42. Santorum JM, Darriba D, Taboada GL, Posada D. Jmodeltest.org: selection of nucleotide substitution models on the cloud. Bioinformatics.

2014;30(9):1310-1311.

43. Ronquist F, Huelsenbeck JP. MrBayes 3: Bayesian phylogenetic inference under mixed models. Bioinformatics. 2003;19(12):1572-1574.

44. Ronquist F, Teslenko M, Mark PVD, Ayres DL, Darling A, Höhna S, Larget B, Liu L, Suchard MA, Huelsenbeck JP. MrBayes 3.2: efficient Bayesian phylogenetic inference and model choice across a large model space. Systematic Biology. 2012;61(3):539-542.

45. Guindon S, Gascuel O. A simple, fast, and accurate algorithm to estimate large phylogenies by maximum likelihood. Systematic Biology. 2003;52(5):696704.

46. Huelsenbeck JP, Ronquist F, Nielsen R, Bollback JP. Bayesian inference of phylogeny and its impact on evolutionary biology. Science. 2001;294(5550):2310-2314.

47. Rambaut A, Drummond AJ. Figtree version 1.4.0 (2012). Available online: http://tree.bio.ed.ac.uk/software/figtree (accessed on 15 May 2021 ).

\section{Figures}
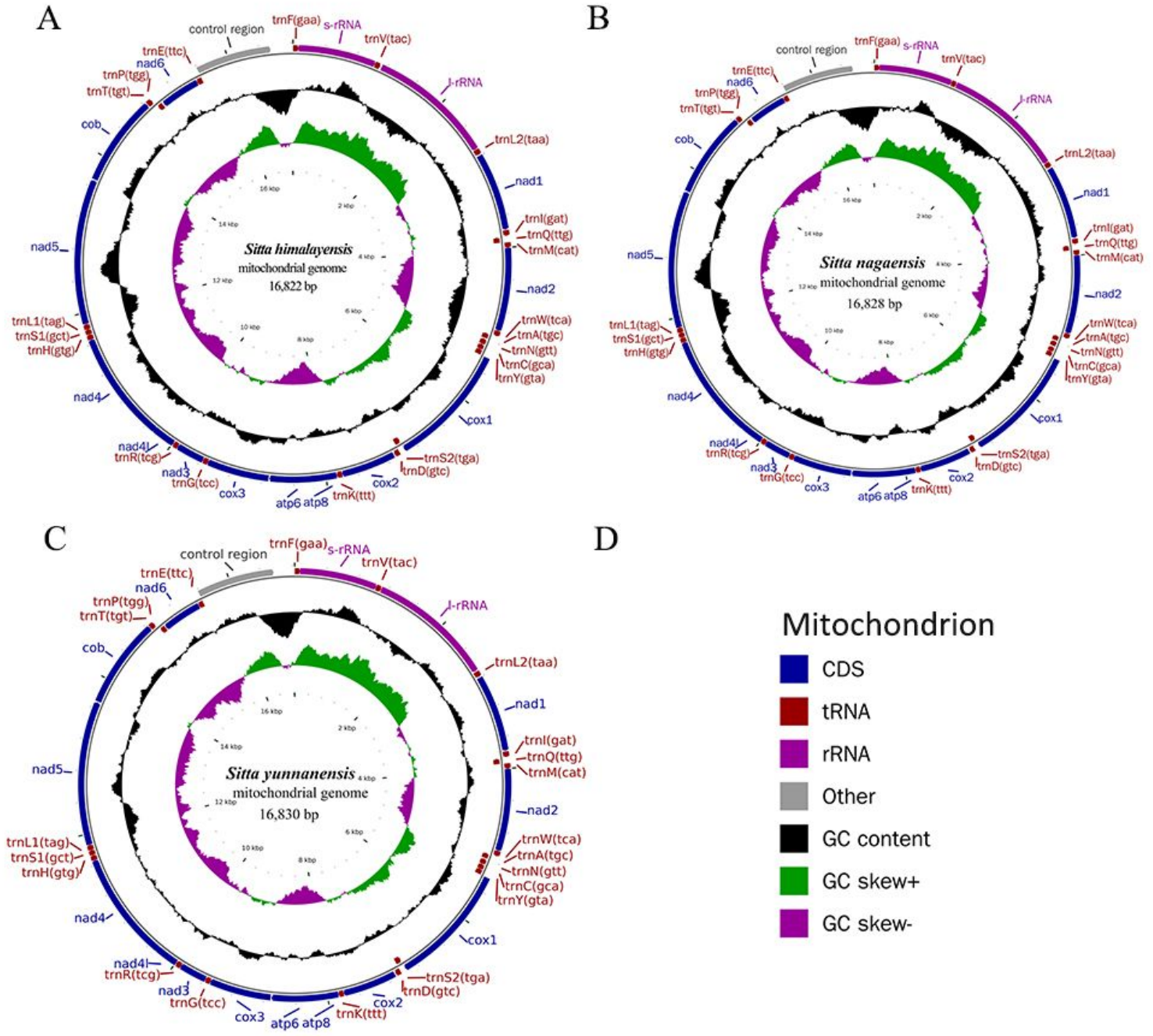

$\mathrm{D}$

Mitochondrion
CDS
tRNA
rRNA
Other
GC content
GC skew-
GC skew-

Figure 1 
Characters of mitochondrial genomes of the three newly sequenced Sitta species. Gene names are annotated using standard abbreviations; single letters indicate corresponding amino acids based on the IUPAC-IUB abbreviation. A: S. himalayensis mitochondrial genome. B: S. nagaensis mitochondrial genome. C: S. yunnanensis mitochondrial genome. The legends are depicted in D.
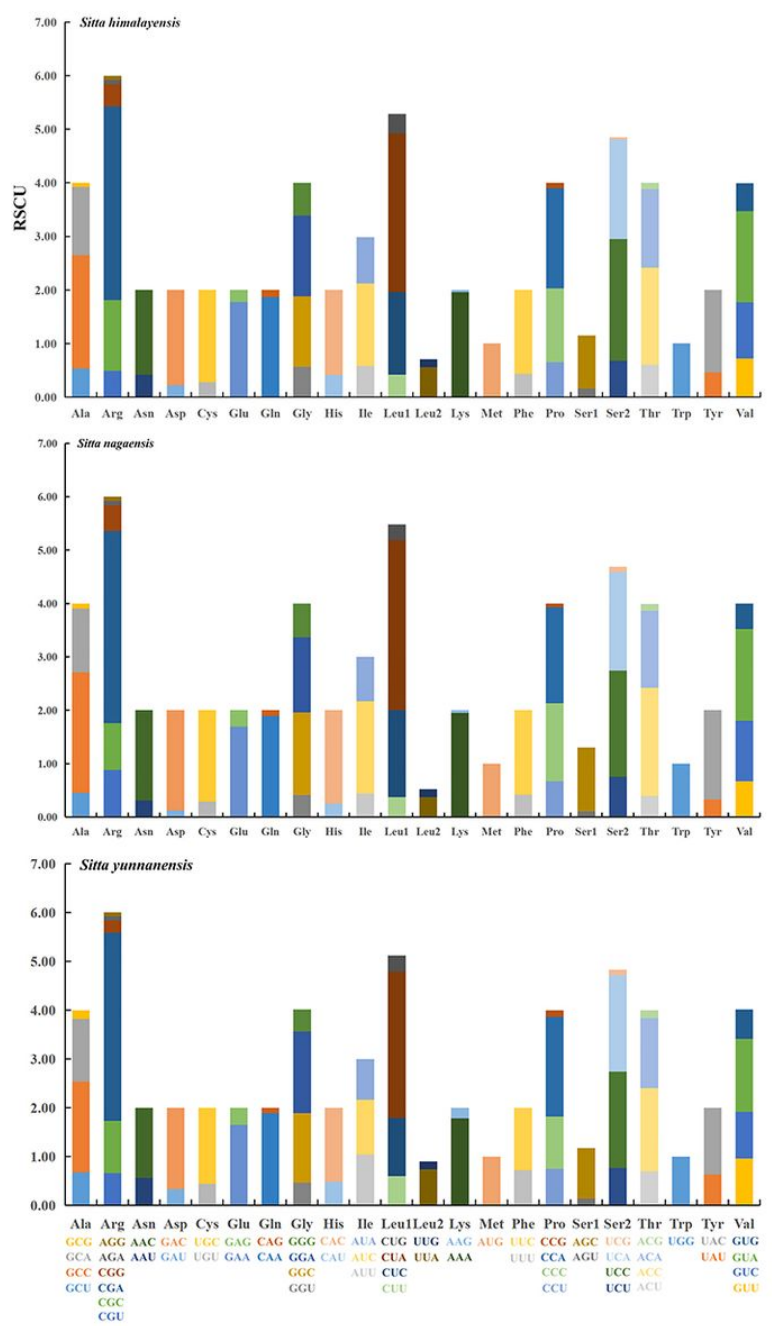

Figure 2

Relative synonymous codon usage (RSCU) for protein-coding genes of the three Sitta mitochondrial genomes. Codon families are provided on the x-axis. 

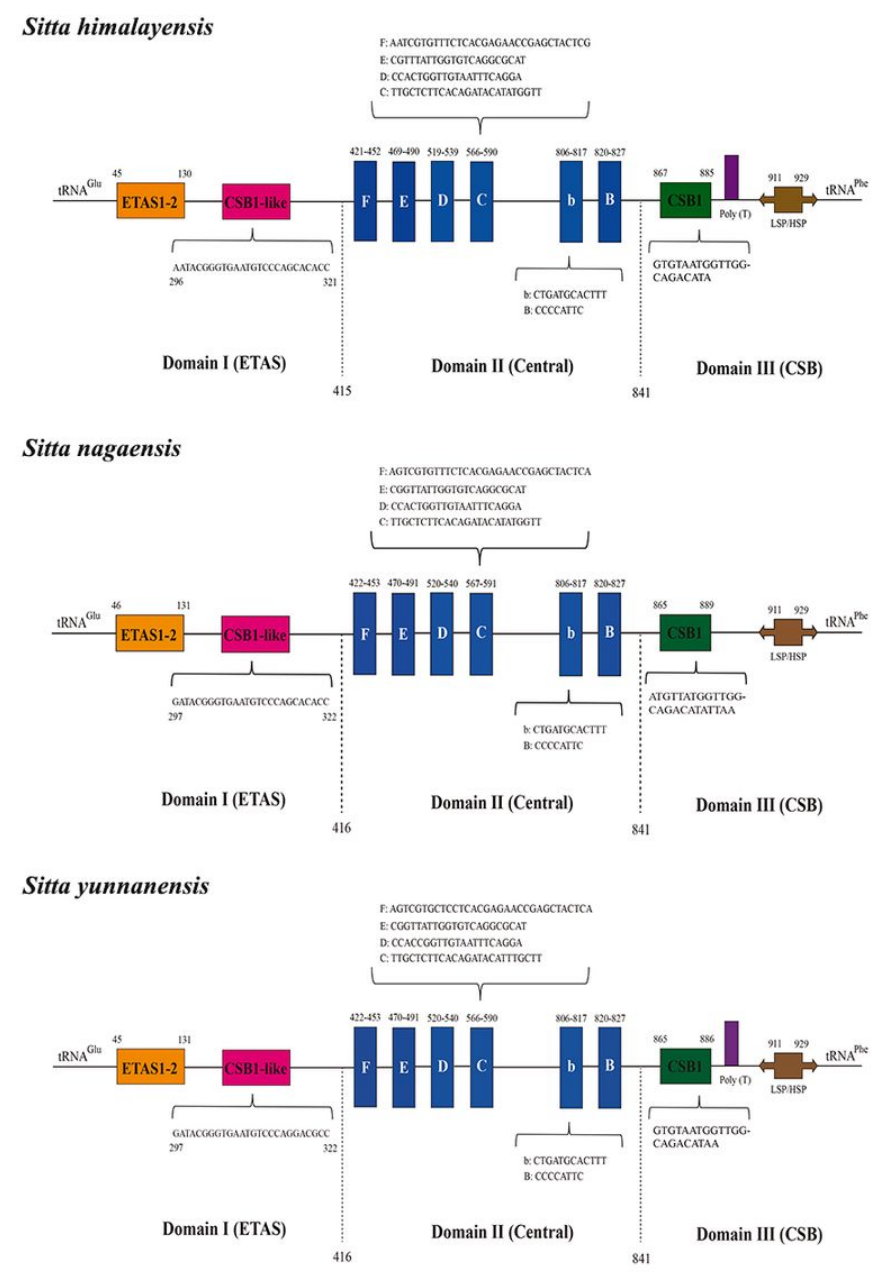

\section{Figure 3}

Predicted structural elements in the control region of three Sitta species. Extended termination-associated sequences are indicated by orange boxes, and conserved sequence blocks are indicated by blue boxes. 


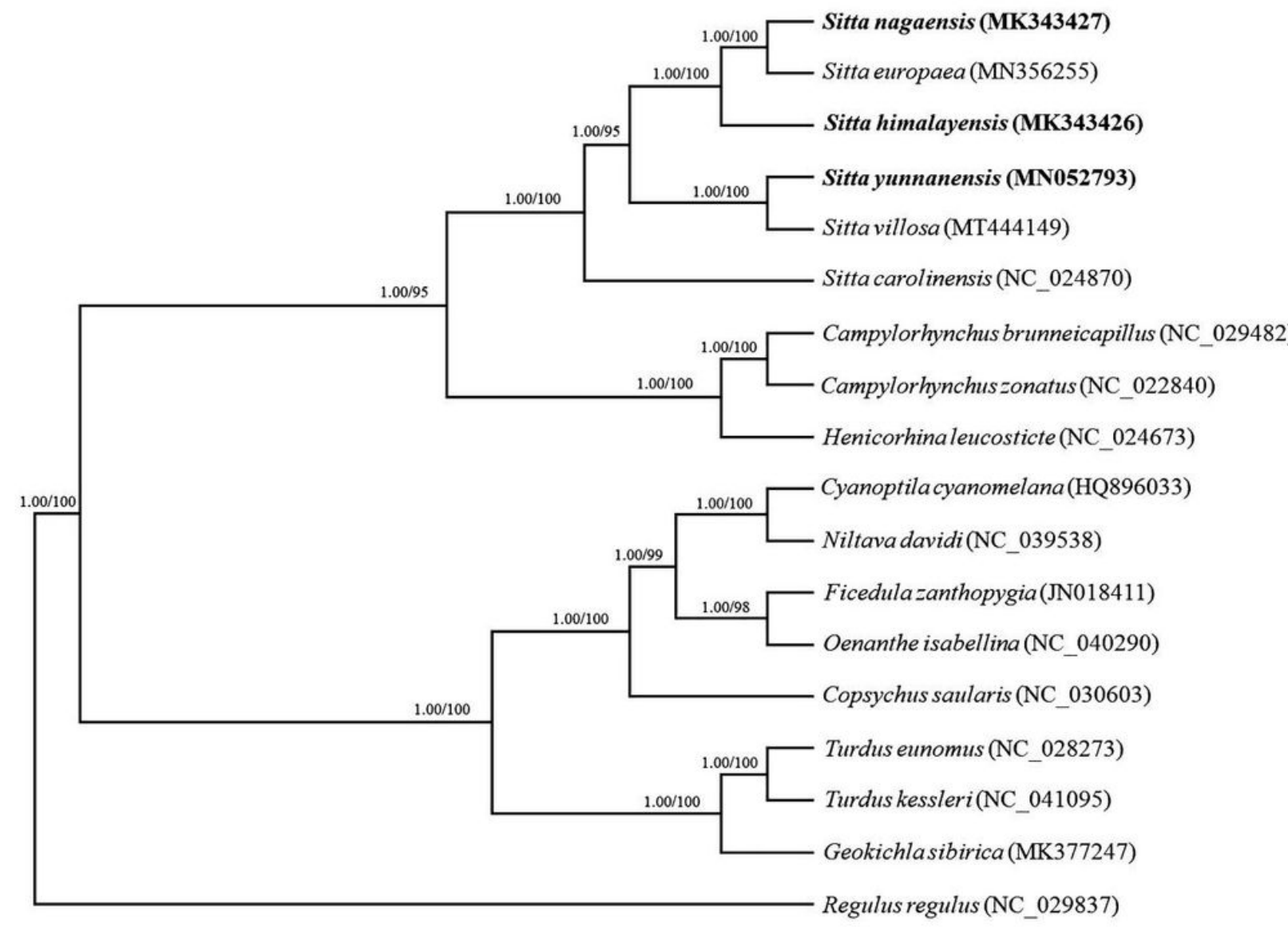

Sittidae

Troglodytidae

Muscicapidae

Turdidae

Outgroup

Figure 4

Phylogeny from Sitta mitochondrial genome sequences. Bayesian inference (BI) and maximum likelihood (ML) analyses inferred from protein-coding genes supported the same topological structure. Values at nodes are Bayesian posterior probabilities and ML bootstrap values. The tree is rooted with one outgroup (Regulus regulus). 